\title{
DIRETRIZES PARA WEBSITES DE TURISMO LGBTQ COM BASE NOS ELEMENTOS DA ARQUITETURA DA INFORMAÇÃO
}

\section{GUIDELINES FOR LGBTQ TOURISM WEBSITES BASED ON INFORMATION ARCHITECTURE ELEMENTS}

\author{
Jean Fernandes Brito a \\ Márcio Matias ${ }^{b}$ \\ Edgar Bisset ${ }^{\mathrm{c}}$
}

\begin{abstract}
RESUMO
Introdução: A presente pesquisa parte da necessidade dos ambientes informacionais digitais considerarem a disposição das informações e vocabulários utilizados, para apresentar conteúdos informacionais com estruturas e linguagens a uma comunidade específica, no caso a comunidade LGBTQ. Ela se justifica pela relevância do tema, Arquitetura da Informação no contexto dos estudos de gênero e sexualidade, por apresentar a questão de grupos tão vulneráveis ao preconceito e à violência na nossa sociedade. Criando, então, lugar para reflexão do poder por meio de websites de turismo LGBTQ com informações bem organizadas como meio de promoção dos direitos, lutas, anseios e receios destes grupos. Objetivo: propor diretrizes nos websites de turismo LGBTQ com base nos aparatos teóricos da Arquitetura da Informação, visando à otimização do acesso e encontrabilidade das informações turísticas nestes websites. Metodologia: Metodologicamente, trata-se de uma pesquisa de natureza qualitativa, de cunho descritivo e analítico e se refere a uma análise de observação direta não participante dos resultados de uma pesquisa realizada anteriormente por Brito (2019); Brito e Matias (2019) visando à proposta e apresentação de diretrizes de Arquitetura da Informação nos websites de turismo LGBTQ brasileiros. Resultados: Como resultados, se apresentaram um grupo de diretrizes para pontuar elementos fundamentais de aplicação aos princípios estruturais da Arquitetura da Informação para o atendimento das necessidades informacionais da comunidade LGBTQ nos websites de turismo. Conclusão: A Comunidade LGBTQ possui necessidades informacionais especificas, que às vezes encontram-se na interface do website, essas necessidades são expressas por meio do vocabulário Pajubá e que devem estar envoltos no contexto da Arquitetura da Informação.
\end{abstract}

\footnotetext{
a Doutorando em Ciência da Informação pela Universidade Estadual Paulista (UNESP). E-mail: jjeanfernandes@gmail.com.

b Doutor em Engenharia de Produção pela Universidade Federal de Santa Catarina (UFSC). Docente do Departamento de Ciência da Informação da Universidade Federal de Santa Catarina (UFSC). E-mail: maatias97@gmail.com.

c Doutor em Ciência da Informação pela Universidade Estadual Paulista (UNESP). Docente do Departamento em Ciência da Informação da Universidade Federal de Santa Catarina (UFSC). E-mail:ebicet@gmail.com.
} 
Descritores: Arquitetura da Informação. Turismo LGBTQ. Gênero. Sexualidade.

\section{INTRODUÇÃO}

Os conteúdos que são disseminados nos ambientes informacionais digitais devem ser estruturados de forma precisa, organizada e disseminada em função dos sujeitos informacionais, para que não haja problemas de acesso e uso. (ALMEIDA; SOUSA; OLIVEIRA, 2018).

Diante disso, Vechiato (2010, p. 42) elucida que os estudos no contexto da Arquitetura da Informação têm-se [...] "alicerçado às propostas de métodos, técnicas, processos e elementos que compõem sua teoria, somados aos respaldos teóricos e metodológicos provenientes, em especial, da Ciência da Informação".

Oliveira e Vidotti (2016, p. 25) afirmam que a Arquitetura da Informação "Trata-se ambientes informacionais que justapõe, articula e integra as partes de organização, de rotulagem, de busca, de navegação e de representação da informação".

$\mathrm{Na}$ literatura nacional encontramos trabalhos relacionados apresentados por Araújo, Bezerra e Oliveira (2018); Brito, Afonso e Matias (2019); Almeida, Sousa e Oliveira (2018); que discutiram Arquitetura da Informação no contexto de estudos de gênero e da comunidade LGBTQ. No âmbito da produção cientifica internacional Law e Ngai (2005); Morosan e Fesenmaier (2007) estudaram os websites de viagens com enfoque da usabilidade e Arquitetura da Informação bem como a percepção dos usuários nessas plataformas. Law e Ngai (2005) sinalizam em seus trabalhos uma incipiência na literatura de estudos que discutem websites de turismo sob o enfoque da experiência do usuário, Arquitetura da Informação e Usabilidade.

Nesse sentido, esta pesquisa tem como objeto de investigação os websites de turismo LGBTQ no contexto dos elementos da Arquitetura da Informação. Diante disso, se identifica como problema de pesquisa, a necessidade dos ambientes informacionais digitais considerarem a disposição das informações e vocabulários utilizados, para apresentar conteúdos informacionais com estruturas e linguagens a uma comunidade específica, no caso a comunidade LGBTQ. 
Após as considerações apresentadas, indagamos: Como um website de turismo LGBTQ pode ser construído e planejado com base nos elementos da Arquitetura da Informação? Quais diretrizes devem compor uma análise de um website de turismo LGBTQ?

Assim o objetivo dessa pesquisa é propor e apresentar diretrizes para análise e construção de websites de turismo LGBTQ com base nos elementos da Arquitetura da Informação.

Metodologicamente, trata-se de uma pesquisa de natureza qualitativa, de cunho descritivo e analítico. Ela se justifica pela relevância dos estudos sobre Arquitetura da Informação no contexto dos estudos de gênero e sexualidade, por apresentar a questão de grupos tão vulneráveis ao preconceito e à violência na nossa sociedade. Criando, então, lugar pra reflexão do poder por meio de websites de turismo LGBTQ com informações bem organizadas como meio de promoção dos direitos, lutas, anseios e receios destes grupos.

Para melhor entendimento essa pesquisa está estruturada em seis seções. Sendo a seção 1, considerações iniciais da pesquisa, a seção 2 os Elementos da Arquitetura da Informação, a seção 3 Turismo LGBTQ, seção 4 os aspectos metodológicos, Seção 5 Análise e discussão dos resultados e por fim na seção 6 as Considerações finais.

\section{OS ELEMENTOS DA ARQUITETURA DA INFORMAÇÃO}

Arquitetura da Informação busca a melhoria do fluxo informacional de ambientes informacionais digitais por meio dos seus elementos e contribui desde então para as pesquisas na área da Ciência da Informação envolvendo ambientes digitais, analógicos híbridos (OLIVEIRA, 2014)

A Arquitetura da Informação como área do conhecimento é um caminho para esse tipo de representação em ambientes informacionais digitais. Assim a Arquitetura da Informação pode ser definida como:

[...] a organização de conteúdos informacionais e as formas de armazenamento e preservação (sistemas de organização), representação, descrição e classificação (Sistema de Rotulagem, metadados, tesauro e vocabulário controlado), recuperação (sistema de busca), objetivando a criação de um 
sistema de interação (Sistema de Navegação) no qual o usuário deve interagir facilmente (usabilidade) com autonomia no acesso e uso do conteúdo (acessibilidade) no ambiente hipermídia informacional digital (VIDOTTI; CUSIN; CORRADI, 2008, p. 182)

De modo a sintetizar e entender os elementos da Arquitetura da Informação apresenta-se no quadro 1 a definição de cada sistema

\section{Quadro 1 - Síntese dos Elementos e definições da Arquitetura da Informação}

\begin{tabular}{|c|c|c|c|}
\hline Sistemas & \multicolumn{2}{|r|}{ Elementos } & Definição \\
\hline \multirow{10}{*}{$\begin{array}{l}\text { Sistemas } \\
\text { de } \\
\text { Organizaç } \\
\text { ão }\end{array}$} & \multirow[t]{3}{*}{$\begin{array}{l}\text { Esquemas } \\
\text { exatos }\end{array}$} & Alfabético & $\begin{array}{l}\text { A organização se dá de maneira textual, por } \\
\text { ordem alfabética }\end{array}$ \\
\hline & & Cronológico & A organização se dá por ordem cronológica \\
\hline & & Geográfico & A organização se dá por fatores geográficos \\
\hline & \multirow[t]{4}{*}{$\begin{array}{l}\text { Esquemas } \\
\text { ambíguos }\end{array}$} & Por tópicos & $\begin{array}{l}\text { As informações são organizadas por tópicos } \\
\text { ou assuntos }\end{array}$ \\
\hline & & $\begin{array}{l}\text { Orientados por } \\
\text { tarefas }\end{array}$ & $\begin{array}{l}\text { Organizam conteúdo e aplicativos em uma } \\
\text { coleção de processos, funções e/ou tarefas }\end{array}$ \\
\hline & & $\begin{array}{l}\text { Direcionados a um } \\
\text { público específico }\end{array}$ & $\begin{array}{l}\text { Quando o ambiente informacional digital } \\
\text { possui vários públicos claramente definidos } \\
\text { e é necessário diferenciar o tipo de conteúdo } \\
\text { e acesso para cada um dos grupos; }\end{array}$ \\
\hline & & $\begin{array}{l}\text { Dirigidos } \\
\text { metáforas }\end{array}$ & $\begin{array}{l}\text { São formas de organizar a informação } \\
\text { utilizando metáforas }\end{array}$ \\
\hline & \multirow[t]{3}{*}{$\begin{array}{l}\text { Esquemas } \\
\text { estruturais }\end{array}$} & Hierárquicos & $\begin{array}{l}\text { Obedece à ordenação hierárquica de } \\
\text { classes subordinadas, ou seja, do geral para } \\
\text { específico }\end{array}$ \\
\hline & & Hipertextos & $\begin{array}{l}\text { Pode ser feita do específico para o mais } \\
\text { geral, a partir dos relacionamentos entre } \\
\text { hipertextos }\end{array}$ \\
\hline & & $\begin{array}{l}\text { Classificação social } \\
\text { e ou Folksonomia }\end{array}$ & $\begin{array}{l}\text { A organização é feita a partir da atribuição } \\
\text { de palavras-chave pelo próprio usuário. }\end{array}$ \\
\hline \multirow[t]{2}{*}{$\begin{array}{l}\text { Sistema } \\
\text { de } \\
\text { Navegaçã } \\
\text { o }\end{array}$} & \multirow[t]{2}{*}{$\begin{array}{l}\text { Navegação } \\
\text { integrada }\end{array}$} & Navegação global & $\begin{array}{l}\text { Este elemento deve estar presente em todas } \\
\text { as páginas de um website e geralmente se } \\
\text { localiza no topo de cada página na forma de } \\
\text { uma barra de navegação. Este elemento } \\
\text { permite o acesso direto às principais áreas e } \\
\text { funções do website }\end{array}$ \\
\hline & & Navegação local & $\begin{array}{l}\text { Este elemento tem por função } \\
\text { complementar a navegação global, } \\
\text { oferecendo opções locais de navegação; }\end{array}$ \\
\hline
\end{tabular}




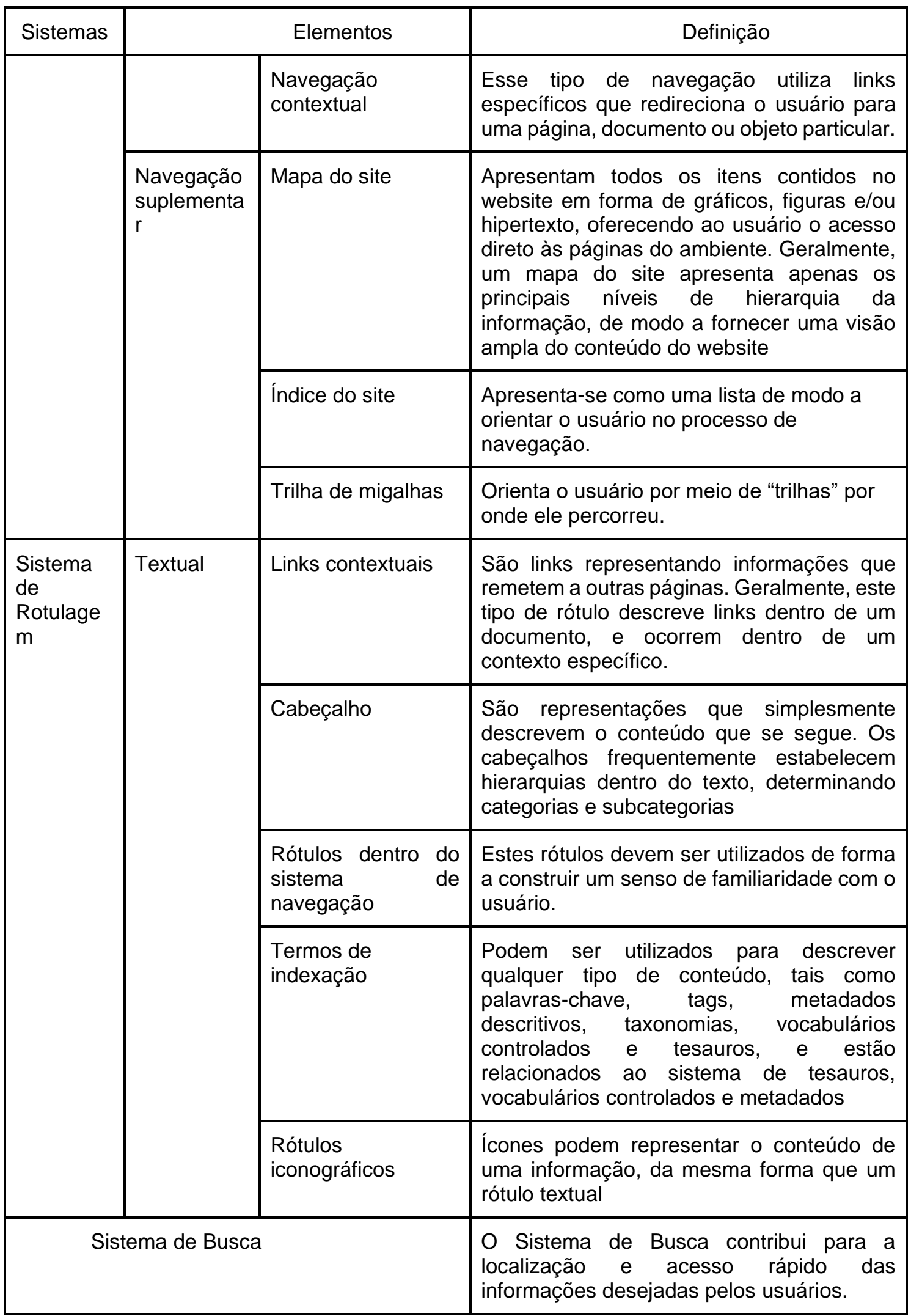

Fonte: Baseado em Rosenfeld, Morville e Arango (2015).

Os autores supracitados também comentam sobre os vocabulários 
controlados, tesauros, metadados e ontologias, considerados também como Sistema de Representação sinalizado por Oliveira e Vidotti (2012).

Dentre todos os elementos e sistemas apresentados, o sistema de Rotulagem é o mais complexo, pois há uma grande possibilidade de erros linguísticos e conceituais passarem despercebidos pelo olhar dos sujeitos informacionais na construção, e manutenção do acesso aos ambientes informacionais digitais. (FERREIRA, 2018).

No contexto da Arquitetura da Informação "o rótulo tem como finalidade comunicar um conceito sem ocupar muito espaço na página e sem demandar muito esforço cognitivo do usuário para compreendê-lo" (REIS, 2007, p. 99).

Nessa relação supracitada com os elementos da Arquitetura da Informação, Ferreira (2018) explica a tríade conteúdo, contexto e usuário no âmbito como um processo de interação e Experiência do Usuário com os ambientes informacionais digitais. Segundo a autora os conceitos são delimitados como sendo:

a) Contexto, de caráter social, cultural e físico;

b) Conteúdo e suas características de funcionalidade, estética e Usabilidade

c) Usuário com suas características individuais que interferem no momento da interação, como os sentimentos, as emoções, as expectativas, a motivação e o prazer desencadeados antes, durante e depois da interação. (FERREIRA, 2018, p.83, grifo nosso)

Além da discussão e apresentação dos sistemas, os autores Rosenfeld e Morville (1998); Rosenfeld, Morville e Arango (2015), argumentam sobre o planejamento que um ambiente informacional deve possuir, entre elas destacam-se: a) esclarecer a missão e a visão dos ambientes informacionais digitais, b) equilibrar as necessidades informacionais, c) determinar os conteúdos e suas funcionalidades e especificar como os sujeitos informacionais encontrarão informações.

De acordo com Camargo (2010) para planejar serviços de disseminação da informação em ambientes informacionais digitais, é preciso se atentar à disponibilidade da instituição em relação às variantes do serviço e a otimização do acesso em ambientes informacionais digitais.

De modo a entender a aplicação dessa pesquisa sobre o objeto de 
investigação na próxima seção serão apresentadas as abordagens do turismo LGBTQ por meio das Tecnologias de Informação e Comunicação.

\section{TURISMO LGBTQ}

"O conceito de turismo sofreu grandes alterações ao longo dos tempos, tendo surgido pela primeira vez em 1910 com o autor austríaco Herman Von Schullern Schrattenhoffen" (OLIVEIRA, 2014, p. 17). A Organização Mundial do Turismo (OMT) explica que o turismo se desenvolve por meio das atividades que são desenvolvidas ao longo de viagens, incluindo festas e entretenimento de um modo geral (OMT, 2001). Em linhas gerais entendemos como:

[...] uma atividade considerada sensível aos fatores políticos, culturais, ambientais, ecológicos, pois imagens negativas na mídia, criminalidade, doenças, falta de atrativos, problemas políticos e terrorismo podem provocar uma queda muito acentuada na visitação de determinada região, ocasionando diversos prejuízos a curto, médio ou até longo prazo. (AZEVEDO et al, 2012, p.494)

O turismo LGBTQ se estabelece como um espaço de sociabilidade da comunidade LGBTQ. Trigo (2009) apresenta uma conceituação de turismo LGBTQ e define como um processo que envolve o planejamento, operação e divulgação de destinos turísticos para o segmento LGBTQ.

Guerra (2015) destaca que o turismo LGBTQ e o envolvimento com as Tecnologias de Informação e Comunicação é uma grande fonte de informação, pois possibilita uma integração e participação da comunidade LGBTQ em diversos aspectos da sociedade em geral, permeando os ambientes informacionais digitais e híbridos.

Vale destacar que o turismo LGBTQ não é apenas um processo ligado ao prazer dos turistas LGBTQ, é também um espaço de conquistas e ativismo que é socializado nos lugares por onde passam. Além disso, Guerra (2015) sinaliza a questão financeira que envolve o turismo LGTBQ, muitos turistas são exigentes e que cobram um desenvolvimento melhor nos seus atendimentos e espaços de lazer.

Segundo Sanches; Mancini; Nascimento (2011) o Turista LGBTQ deseja conhecer uma realidade, com práticas e dinâmicas próprias, por meio do uso das 
Tecnologias de Informação e Comunicação que transmita sensações e prazeres, que possibilite o contato com distintos contextos culturais e ou alternativos ao seu convívio diário. Estas práticas podem ser observadas nos websites de turismo LGBTQ, que propiciam as interações e conexões com os usuários.

Nesse sentido, apresenta-se no contexto internacional a Internacional Gay \& Lesbian Travel Association', (ILGTA) uma associação que foi fundada em 1983 é a principal rede mundial de empresas de turismo acolhedoras para a comunidade LGBTQ, tem por missão promover a igualdade e a segurança no turismo LGBTQ em todo mundo. (INTERNACIONAL GAY\&LESBIAN TRAVEL ASSOCIATION, 2020).

Os membros dessa associação incluem acomodações, transportes, destinos, prestadores de serviços, websites consultores de viagens, operadores turísticos e meios de viagens amigáveis a comunidade LGBTQ também como conhecidos como gay friendly ${ }^{2}$ localizado em mais de 75 países.

No contexto nacional brasileiro temos a Câmara Brasileira de Turismo LGBT $^{3}$ (CBTLGBT), antiga Associação Brasileira de Turismo LGBT (ABTLGBT) sua sede fica na cidade de São Paulo e busca fortalecer o cenário de turismo LGBTQ no Brasil.

A CBTLGT tem a missão de promover o crescimento da oferta turística destinada à comunidade LGBT, fomentando negócio entre os associados e viajantes, no Brasil demonstrando o impacto econômico, midiático e social da comunidade (CAMARA BRASILEIRA DE TURISMO LGBTQ, 2019).

Por fim, estas práticas de vivências no turismo podem ser observadas não só nos websites ou mídias sociais, mas em espaços de festas, que tornam os membros da comunidade livre e sem presenças de homofóbicos, é aí que resulta o poder do turismo LGBTQ, espaço de resistência.

\footnotetext{
1 https://www.iglta.org

${ }^{2}$ Termo em inglês, cuja tradução literal é "amigável aos homossexuais". Lugares que recebem bem homossexuais

${ }^{3} \mathrm{http}: / /$ www.camaralgbt.com.br/
} 


\section{PROCEDIMENTOS METODOLÓGICOS}

A pesquisa se caracteriza como aplicada, descritiva e analítica e possui abordagem qualitativa e se refere a uma análise de observação direta não participante dos resultados de uma pesquisa realizada anteriormente por Brito (2019); Brito e Matias (2019) visando à proposta e apresentação de diretrizes de Arquitetura da Informação nos websites de turismo LGBTQ brasileiros.

As referidas pesquisas mencionadas contemplam dois momentos: Primeiramente, Brito (2019) realizou a observação direta por meio da Arquitetura da Informação em seis websites de turismo LGBTQ brasileiros.

A análise foi realizada com base nos elementos da Arquitetura da Informação, quais sejam: Organização, Navegação, Rotulagem e Busca o que permitiu a identificação de elementos necessários para os websites. Posteriormente foi feita uma análise detalhada com todos os rótulos (iconográficos, textuais e imagéticos) visando os termos do vocabulário Pajubá ${ }^{4}$ e conteúdos LGBTQ.

Os websites escolhidos para a pesquisa são os websites de turismo LGBTQ brasileiros apresentados na tabela 1.

Tabela 1 - Tamanho dos websites

\begin{tabular}{|c|c|c|}
\hline Website & URL & $\begin{array}{l}\text { Tamanho do } \\
\text { website }\end{array}$ \\
\hline Guia Gay São Paulo & $\begin{array}{l}\text { http://www.guiagaysaopaulo.com. } \\
\text { br }\end{array}$ & 12.200 páginas \\
\hline Viaja Bi & https://viajabi.com. br/ & 995 páginas \\
\hline Guia Gay Rio & http://www.guiagayrio.com.br & 407 páginas \\
\hline Viajay & http://viajay.com.br/ & 817 páginas \\
\hline FriendlyTur & http://www.friendlytur.com.br/ & 1050 páginas \\
\hline Viagem LGBT & http://viagemlgbt.com.br/ & 593 páginas \\
\hline
\end{tabular}

Fonte: Dados da pesquisa, 2020.

De modo a recuperar a quantidade de páginas e identificar o tamanho do site foi utilizado o comando webométrico "site: xxx.com. BR" no buscador Google no dia 05 de novembro de 2019. Para a escolha dos websites foi realizada uma

\footnotetext{
${ }^{4}$ O Pajubá é uma linguagem de variação do lorubá, este último é um dialeto de origem africana, que foi apropriado e resignificadopela comunidade LGBTQ (NASCIMENTO, 2015).
} 
pesquisa com os termos website turismo + LGBTQ .

Vale destacar que além destes websites apresentados identificados na tabela 1, a Rede Guia Gay está presente em outros municípios, quais sejam: Guia Gay Floripa, Guia Gay Belo Horizonte, Guia Gay Brasília e Guia Gay Salvador, entretanto, por apresentarem a mesma interface, escolheu-se 0 maior, o Guia Gay São Paulo. O guia Gay Rio apresenta o mesmo nome, mas não faz parte da mesma rede de websites, inclusive a sua interface é diferente dos demais.

Por fim, a análise dos elementos da Arquitetura da Informação e o detalhamento dos rótulos permitiram a identificação de elementos necessários para a apresentação e construção das diretrizes nos websites de turismo LGBTQ, que serão descritos na próxima seção.

\section{DIRETRIZES NOS WEBSITES DE TURISMO LGBTQ COM BASE NOS ELEMENTOS DA ARQUITETURA DA INFORMAÇÃO}

A proposta de construção das diretrizes visa pontuar elementos fundamentais de aplicação aos princípios estruturais da Arquitetura da Informação para atendimento das necessidades informacionais da comunidade LGBTQ nos websites de turismo.

Segundo Camargo e Vidotti (2011) as diretrizes são consideradas recomendações a serem realizadas ou checadas como oferecer menus de seleção, disponibilizar funções-chave em ambientes informacionais digitais.

Diante disso, para a apresentação das diretrizes, adaptou-se a estrutura proposta por Sanchez (2018), na qual a autora apresenta três pontos na estrutura: Ação, Recurso e Apresentação.

a) Ação: Significa o que deve ser realizado ou melhorado;

b) Recurso: Apresenta o que deve ser implementado;

c) Diretrizes: Apresentação das melhorias e recomendações. 


\section{Quadro 2 - Diretrizes e recomendações de análise de websites de turismo LGBTQ}

\begin{tabular}{|c|c|c|c|}
\hline AÇÃO & RECURSO & DIRETRIZES & AUTORES \\
\hline Implementar & $\begin{array}{l}\text { Classificação } \\
\text { Social ou } \\
\text { Folksonomia }\end{array}$ & $\begin{array}{l}\text { Possibilidade nas notícias ou nos } \\
\text { comentários a inserção dos termos por } \\
\text { partes dos sujeitos informacionais de } \\
\text { acordo com suas necessidades. }\end{array}$ & $\begin{array}{c}\text { Vechiato e } \\
\text { Vidotti (2014) }\end{array}$ \\
\hline Adequar & $\begin{array}{l}\text { Mecanismo de } \\
\text { Busca Simples }\end{array}$ & $\begin{array}{l}\text { Destaque: estar em evidência na } \\
\text { página, evitando os menus laterais, } \\
\text { como por exemplo, uma caixa de busca } \\
\text { centralizada; Localização: fazer parte } \\
\text { de um menu global, para que o usuário } \\
\text { não tenha que retornar a página inicial } \\
\text { para mudar sua pesquisa; Tamanho: O } \\
\text { mecanismo de busca deve ter tamanho } \\
\text { médio/grande, destacando-se dos } \\
\text { demais campos; Filtros: A adição de } \\
\text { filtros deve ser destacada na página } \\
\text { inicial, propiciando a busca tanto pelo } \\
\text { mecanismo de busca simples, quanto } \\
\text { no mecanismo }\end{array}$ & $\begin{array}{l}\text { Rosenfeld, } \\
\text { Morville } \\
\text { Arango (2015) } \\
\text { Sanchez } \\
\text { (2018 p. 148) }\end{array}$ \\
\hline Disponibilizar & $\begin{array}{l}\text { Mecanismo de } \\
\text { busca avançado }\end{array}$ & $\begin{array}{l}\text { Apresentar recurso na página inicial; } \\
\text { Deixar em evidência a possibilidade de } \\
\text { mudança do mecanismo de busca } \\
\text { simples para o mecanismo busca } \\
\text { avançada. Assim os sujeitos } \\
\text { informacionais conseguem recuperar o } \\
\text { termo de acordo com suas } \\
\text { necessidades. }\end{array}$ & $\begin{array}{l}\text { Rosenfeld, } \\
\text { Morville } \\
\text { Arango (2015) }\end{array}$ \\
\hline Atribuir & $\begin{array}{l}\text { Rótulos do } \\
\text { Vocabulário } \\
\text { Pajubá }\end{array}$ & $\begin{array}{l}\text { Apresentar rótulos atribuídos dentro } \\
\text { dos sistemas de organização e } \\
\text { navegação, oriundos do vocabulário } \\
\text { Pajubá (utilizado por usuários da } \\
\text { comunidade LGBTQ). Além disso, a } \\
\text { associação de rótulos imagéticos para } \\
\text { facilitar o processo de identificação. }\end{array}$ & $\begin{array}{l}\text { Reis (2007) } \\
\text { Brito; Silva; } \\
\text { Matias (2017) }\end{array}$ \\
\hline Readequar & $\begin{array}{c}\text { Conteúdo } \\
\text { informacional a } \\
\text { todo o acrônimo } \\
\text { LGBTQ }\end{array}$ & $\begin{array}{l}\text { Apresentar conteúdos de informações } \\
\text { turísticas de modo atender todo o } \\
\text { acrônimo LGBTQ. Preferencialmente } \\
\text { um menu de navegação com } \\
\text { conteúdos específicos: GAYS, } \\
\text { LÉSBICAS, BISSEXUAIS, } \\
\text { TRAVESTIS E PESSOAS TRANS. }\end{array}$ & $\begin{array}{l}\text { Corradi (2007) } \\
\quad \text { Straioto } \\
\quad(2002) ; \\
\text { Brito, Afonso e } \\
\text { Matias (2019) }\end{array}$ \\
\hline \multirow{2}{*}{ Aprimorar } & $\begin{array}{l}\text { Sistema de } \\
\text { Organização }\end{array}$ & $\begin{array}{l}\text { Apresentar possibilidade de nuvem de } \\
\text { tags criado pelos próprios sujeitos } \\
\text { informacionais. }\end{array}$ & $\begin{array}{c}\text { Rosenfeld, } \\
\text { Morville } \\
\text { Arango (2015) }\end{array}$ \\
\hline & $\begin{array}{l}\text { Sistema de } \\
\text { Navegação }\end{array}$ & $\begin{array}{l}\text { Apresentar mapa do Site e índice, bem } \\
\text { como elementos suplementares de } \\
\text { navegação, nuvem de tags. }\end{array}$ & $\begin{array}{l}\text { Rosenfeld, } \\
\text { Morville } \\
\text { Arango (2015) }\end{array}$ \\
\hline Criar & $\begin{array}{l}\text { Missão, visão do } \\
\text { website }\end{array}$ & $\begin{array}{l}\text { Deixar em evidência os objetivos, a } \\
\text { missão e visão do website. } \\
\text { Principalmente se o seu objetivo for } \\
\text { atender apenas uma parte do acrônimo } \\
\text { da sigla LGBTQ. }\end{array}$ & $\begin{array}{c}\text { Rosenfeld, } \\
\text { Morville } \\
\text { Arango (2015) } \\
\text { Corradi(2007) }\end{array}$ \\
\hline
\end{tabular}

Fonte: Dados da pesquisa, 2019. 
a) Implementar a Classificação Social e ou Folksonomia possibilidade de incluir os termos nas notícias ou nos comentários por partes dos sujeitos informacionais de acordo com suas necessidades. Em um website de turismo LGBTQ essa implementação permitirá a participação efetiva dos sujeitos propiciando uma interação e construção colaborativa de suas necessidades ao buscar as informações turísticas.

Nesse sentido Vechiato e Vidotti (2014) comentam que o comportamento linguístico dos usuários no momento de busca de informação bem como na classificação social ou representação colaborativa dos recursos informacionais (folksonomia) deve ser clara e precisa. A comunidade LGBTQ se apropria dos símbolos linguísticos, do vocabulário Pajubá para atender as necessidades. Essa recomendação foi necessária, pois nenhum website permite a inserção de tags pelo próprios sujeitos informacionais. O website Guia Gay São Paulo apresenta os termos, no entanto são termos desenvolvidos pelo próprio sistema.

b) Adequar Mecanismo de Busca Simples - estar em evidência na página, , uma caixa de busca centralizada; Localização: fazer parte de um menu global, para que os sujeitos informacionais não tenha que retornar a página inicial para mudar sua pesquisa; Tamanho: 0 mecanismo de busca deve ter tamanho médio/grande, destacando-se dos demais campos. (SANCHEZ, 2018)

Sanchez (2018) comenta sobre a adoção de filtros, que deve ser destacada na página inicial, propiciando a busca tanto pelo mecanismo de busca simples, quanto no mecanismo de busca avançada. Essa recomendação foi considerada, pois nos ambientes avaliados apenas quatro possuem sistema de busca, quais sejam: Guia Gay São Paulo, Viajabi, Friendly Tur, e Viagem LGBT.

c) Disponibilizar Mecanismo de Busca Avançada - apresentar recurso na página inicial; Deixar em evidência a possibilidade de mudança do mecanismo de busca simples para o mecanismo busca avançada. Assim os sujeitos informacionais conseguem recuperar o termo de acordo com suas necessidades.

O planejamento do sistema de busca deve considerar, de acordo com, 
Rosenfeld, Morville e Arango (2015), os tipos de informações que desejam recuperar e o detalhamento na visualização da informação (simples, detalhado, ordem cronológica, alfabética, relevância). Destaca-se que nenhuns dos websites avaliados apresentaram sistema de busca avançada, tampouco a realizações de combinações com os termos.

d) Atribuir rótulos do Vocabulário Pajubá - rótulos atribuídos dentro dos sistemas de organização e navegação, oriundos do vocabulário Pajubá. Além disso, a incluir à associação de rótulos imagéticos para facilitar o processo de identificação. O vocabulário Pajubá como foi apresentado anteriormente além de ser um dialeto é forma de expressar da comunidade LGBTQ, visto que esses termos incluem as suas necessidades informacionais no contexto dos websites de turismo LGBTQ.

Conforme Le Coadic (1996) usar a informação é trabalhar com a matéria informação para se obter um efeito satisfatório em detrimento de uma necessidade de informação. O olhar dos sujeitos informacionais sustenta a compreensão dos motivos pelos quais as pessoas se envolvem num processo de busca informacional. Vale destacar que apenas 3 websites utilizaram termos do vocabulário Pajubá, quais sejam: Guia Gay São Paulo, Viagem LGBT, Viaja $\mathrm{Bi}$ e FriendlyTur. Entretanto não basta incluir termos do vocabulário pajubá, devem-se apresentar elementos e conteúdos informacionais que satisfaçam essas necessidades de toda a comunidade LGBTQ.

e) Readequar Conteúdo informacional a todo o acrônimo LGBTQ apresentar conteúdos de modo atender todo o acrônimo LGBTQ. Preferencialmente um menu de navegação com conteúdos específicos: GAYS, LÉSBICAS, BISSEXUAIS, TRAVESTIS E PESSOAS TRANS.

Corradi (2007) comenta que os conteúdos informacionais em ambientes informacionais digitais devem ser objetivos, navegáveis e visíveis aos sujeitos informacionais. A autora afirma ainda que relacionada à rapidez encontra-se a navegabilidade, que visa tornar o ambiente mais visível, com destaque às determinadas informações. Com isso pretende-se melhorar a usabilidade de 
ambientes informacionais gerais e específicos.

Os conteúdos informacionais dispostos nesses ambientes de turismo LGBTQ atendem em sua grande maioria aos gays masculinos conforme apontou pesquisas de Brito e Matias (2019) e Magalhães (2018), ou seja, há uma invisibilidade das Lésbicas, Bissexuais, Travestis, Transexuais e Queer na estruturação desses ambientes informacionais. Enfim, desenvolver um website de turismo LGBTQ, deve atender as necessidades de todos os que pertencem a essa comunidade.

f) Aprimorar o Sistema de Navegação e Organização - Incluir os elementos suplementares de navegação, Mapa do Site, índice, bem como a inclusão de nuvem de tags no processo de navegação.

Corradi (2007); Rosenfeld, Morville e Arango (2015) comentam que o planejamento de um sistema de navegação e organização na composição de uma Arquitetura da Informação, torna-se essencial para a apresentação contextualizada da informação, auxiliando os sujeitos informacionais em suas buscas de forma dinâmica e flexível com autonomia e independência em sua movimentação pelo ambiente informacional digital. No processo de avaliação dos websites destaca-se os websites analisados valem dos elementos de navegação do tipo embutida. Já, a utilização da navegação suplementar foi localizada em apenas 3 websites: Guia Gay São Paulo, Viagem LGBT, Viaja Bi apresentam apenas trilhas de migalhas. Nenhum website apresenta mapa do site ou índice no processo de Navegação.

g) Criar: Missão, Visão do Website - deixar explícitos os objetivos, a missão e visão do website. Principalmente se o seu objetivo for atender apenas uma parte do acrônimo. (Ex: Website para atender apenas as lésbicas, apenas as Travestis, bissexuais)

Corradi (2007) explica que as Informações sobre o ambiente informacional digital, a URL, a instituição responsável, a identificação do avaliador ou o desenvolvedor e a data são fundamentais na caracterização do analista ou criador do website, ou de qualquer outro ambiente digital. Estas informações legitimam a natureza do ambiente digital. A data é essencial para a identificação da criação e análise do ambiente, considerando-se que os websites 
são atualizados, alteram sua interface e layout com frequência. Apenas o website ViajaBi deixa evidente qual a missão e os objetivos do website.

Na figura 1 apresenta- se a tríade, conteúdo, contexto e usuário no contexto da aplicação dessa pesquisa

\section{Figura 1 - Tríade no contexto da pesquisa}

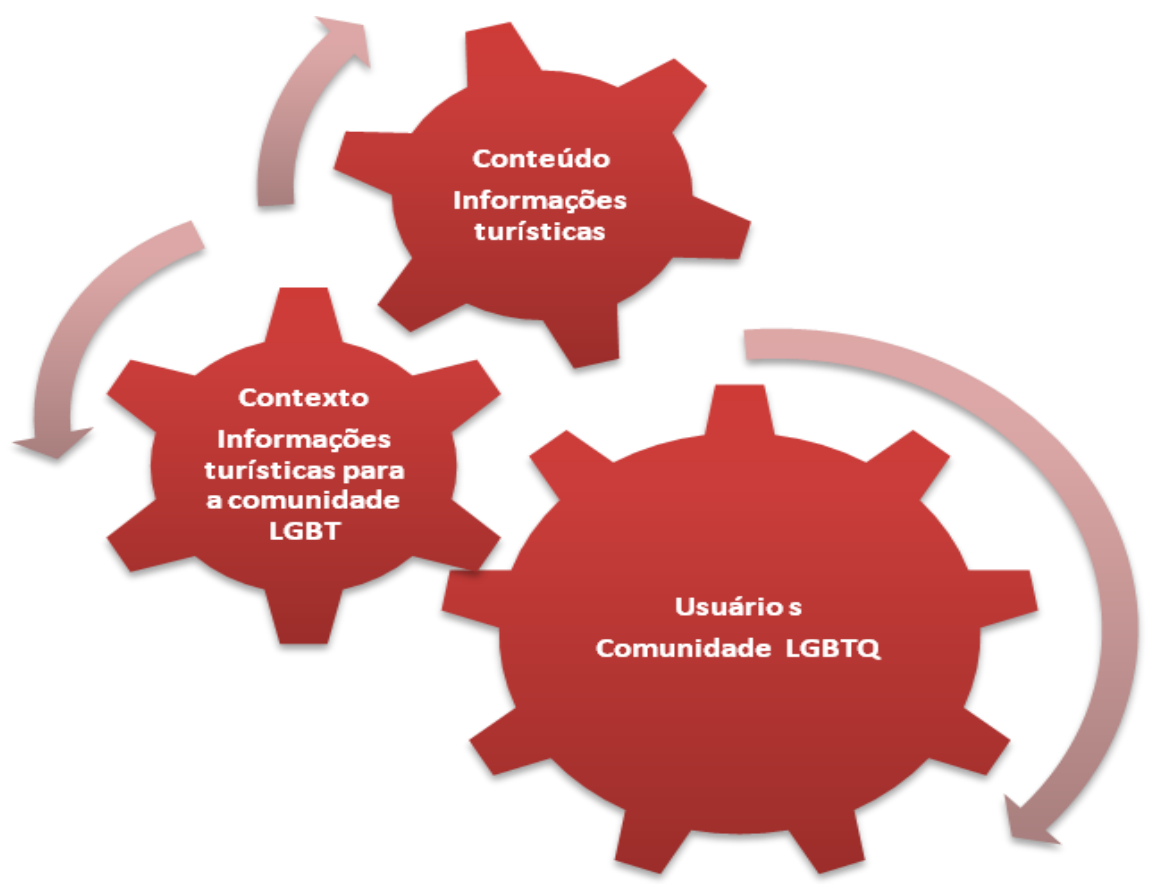

Fonte: Elaboração própria, 2019.

O conteúdo dos websites de turismo LGBTQ são informações turísticas para todo o Acrônimo, Lésbicas, Gays, Bissexuais, Transgêneros e Queer no contexto da própria comunidade para a os sujeitos informacionais em questão. Os desenvolvedores devem refletir sobre essa tríade ao aprimorar, criar e desenvolver websites de turismo que envolve a comunidade LGBTQ.

Nessa tríade associa-se a ideia do Paradigma Social da Informação principalmente, a importância da sociedade como uma influenciadora no processo de construção de conhecimento realizada pelo indivíduo. Portanto, ao se falar, neste caso, de um usuário pertencente a uma comunidade LGBTQ, é preciso falar da realidade desta comunidade, deste ambiente que é influenciador e, por vezes, determinante na busca de informação e nas fontes utilizadas por tais pessoas. E é por isso que se faz necessário um diálogo entre os ambientes informacionais digitais e a comunidade LGBTQ. 
Por meio disso, as diretrizes propostas nessa investigação estão direcionadas, em sua maioria, as melhorias dos mecanismos de busca e ao conteúdo informacional, abrindo a possibilidade de participação de toda a comunidade LGBTQ.

A atenção para este recurso foi maior, devido aos resultados obtidos com as análises e caracterização dos rótulos em que há uma ausência de sistema de busca simples e busca avançada, bem como a existência de conteúdo apenas para os gays.

O desempenho desses mecanismos determina a qualidade e o sucesso de website de turismo LGBTQ em atender as necessidades informacionais da comunidade. Os atributos da Arquitetura da Informação recomendados podem potencializar o funcionamento desses ambientes, o que pode afetar, diretamente, na visibilidade das informações turísticas para a comunidade LGBTQ.

\section{CONSIDERAÇÕES FINAIS}

A aplicação e estudo dos elementos da Arquitetura da informação facilitam a organização, a navegação e busca das informações pelos usuários. Percebeu-se, durante a análise dos ambientes e a construção das diretrizes, a ausência de elementos que poderiam facilitar a busca e a recuperação; como exemplo, ausência do refinamento da busca mapa do site, classificação social que apresentaria uma visão global dos websites de turismo LGBTQ.

As diretrizes destinadas à melhoria da Arquitetura da Informação nos websites foram construídas a partir da avaliação da Arquitetura da Informação nos ambientes selecionados.

A Comunidade LGBTQ possui necessidades informacionais especificas, que às vezes encontram-se na interface do website, essas necessidades são expressas por meio do vocabulário Pajubá e que devem estar envoltos no contexto da Arquitetura da Informação.

A utilização de rótulos do vocabulário Pajubá é muito baixa, desse modo infere-se que o website demanda investimentos neste quesito para atender a 
todos os segmentos LGBTQ, pois o sistema de rotulagem é fundamental para a estruturação deste tipo de website, na medida em que este sistema está diretamente ligado aos conteúdos em questão, e se configura e desenha as necessidades e demandas informacionais dessa comunidade.

A utilização de uma arquitetura informacional bem planejada pode facilitar o processo de desenvolvimento, auxiliar na estruturação das informações e adequar os ambientes informacionais digitais colaborativos.

Após as considerações apresentadas nos permite afirmar que outras pesquisas poderão surgir do processo investigativo, de modo que sugerimos uma lista de pesquisas envolvendo a Arquitetura da Informação e Tecnologias no contexto do turismo LGBTQ, quais sejam: a) Um modelo de Arquitetura da Informação para ambientes de turismo LGBTQ; b) Investigação das Tecnologias de Informação e Comunicação em dispositivos moveis para a comunidade LGBTQ; c) Mídias Sociais como espaço de ativismo e sociabilidade da comunidade LGBTQ d) Arquitetura da Informação pervasiva em ambiências LGBTQ.

\section{REFERÊNCIAS}

ALMEIDA, G. B. C.; SOUSA, A. K. N.; OLIVEIRA, H. P. C. Arquitetura da informação no contexto de gênero: uma análise do website da Secretaria Especial de Políticas para Mulheres. Ciência da informação em revista, Alagoas, v. 5, n. 3, p. 30-42, 2018. Disponível em:

https://www.seer.ufal.br/index.php/cir/article/view/5601. Acesso em 19 out. 2020.

ARAUJO, A. R. S.; BEZERRA, M. G.; OLIVEIRA, H. P. C. Arquitetura da informação no website Geledés: a mulher negra em foco. Informação em Pauta, Fortaleza, v. 3, n. 1, p. 97-112, 2018. Disponível em: http://www.periodicos.ufc.br/informacaoempauta/article/view/32480/72986. Acesso em 19 out. 2020.

AZEVEDO, M. S.; MARTINS, C. B.; NÁDIA, P. K.; FARAH, O. E. Segmentação no setor turístico: o turista LGBT de São Paulo. Revista de Administração da Universidade Federal de Santa Maria, Santa Maria, v. 5, n. 3, p. 493-506, 2012. Disponível em: https://periodicos.ufsm.br/index.php/reaufsm/article/view/3852/pdf. Acesso em: 19. out. 2020 
BRITO, J. F. Arquitetura da Informação em websites de turismo LGBTQ. 2019. Dissertação (Mestrado em Ciência da Informação) - Universidade Federal de Santa Catarina, Florianópolis, 2019. Disponível em: https://repositorio.ufsc.br/handle/123456789/198986. Acesso em 19 out. 2020.

BRITO, J. F.; AFONSO, R.; MATIAS, M. Arquitetura Da Informação Com Enfoque Semiótico No Guia Gay São Paulo. Brazilian Journal of Information Science: research trends, Marília, v. 13, n. 1, p. 68-76, 2019. Disponível em: https://revistas.marilia.unesp.br/index.php/bjis/article/view/8309/5647. Acesso em 19 out. 2020.

BRITO, J. F.; SILVA, R. C; MATIAS, M. Arquitetura da Informação e Sintaxe das linguagens imagéticas no website Guia Gay Floripa. In: WORKSHOP DE INFORMAÇÃO, DADOS E TECNOLOGIA WIDAT, 1, 2017, Florianópolis.

Anais [...]. Florianópolis: Universidade Federal de Santa Catarina, 2017. p. 1-8. Disponível em:

https://repositorio.ufsc.br/bitstream/handle/123456789/180296/ST3.5.pdf?seque nce $=1$ \&isAllowed=y. Acesso em 19 out. 2020.

BRITO, J. F.; MATIAS, M. Arquitetura da Informação em websites de turismo LGBTQI+: um enfoque no sistema de rotulagem no website ViajaBi. In: ENCONTRO NACIONAL DE PESQUISA EM CIÊNCIA DA INFORMAÇÃO (ENANCIB), 20, 2019, Florianópolis. Anais [...]. Florianópolis: Universidade Federal de Santa Catarina, 2019. p. 1-20. Disponível em: https://conferencias.ufsc.br/index.php/enancib/2019/paper/view/1188/632. Acesso em 19 out. 2020.

CAMARA BRASILEIRA DE TURISMO LBTQ. Câmara LGBT. Rio de Janeiro, 2019. Disponível em: https://www.camaralgbt.com.br/. Acesso em: 02 fev. 2020.

CAMARGO, L. S. A. de. Metodologia de desenvolvimento de ambientes informacionais digitais a partir dos princípios da Arquitetura da Informação. 2010. Tese (Doutorado em Ciência da Informação) - Faculdade de Filosofia e Ciências, Universidade Estadual Paulista, 2010. Disponível em: https://repositorio.unesp.br/handle/11449/103357. Acesso em: 12 maio 2019.

CAMARGO, L. S. A. de; VIDOTTI, S. A. B. G. Arquitetura da informação: uma abordagem prática para o tratamento de conteúdo e interface em ambientes informacionais digitais. Rio de Janeiro: LTC, 2011.

CORRADI, J. A. M. Ambientes informacionais digitais e usuários surdos: questões de acessibilidade. 2007. Dissertação (Mestrado em Ciência da Informação) - Universidade Estadual Paulista, Faculdade de Filosofia e Ciências, 2007. Disponível em: https://www.marilia.unesp.br/Home/PosGraduacao/Cienciadalnformacao/Dissertacoes/corradi_jam_me_mar.pdf. Acesso em: 12 maio 2019. 
FERREIRA, A. M. J. F. C. As contribuições da Experiência do Usuário para Arquitetura da Informação. 2018. Tese (Doutorado em Ciência da Informação) - Faculdade de Filosofia e Ciências, Universidade Estadual Paulista, 2018. Disponível em:

https://repositorio.unesp.br/handle/11449/157487. Acesso em: 12 maio 2019.

GUERRA, Á. R. D. T. O Turismo LGBT em Brasília: desafios do lazer e da hospitalidade. 2015. Dissertação (Mestrado em Turismo) - Centro de Excelência em Turismo, Universidade de Brasília, 2015. Disponível em: http://repositorio.unb.br/handle/10482/18346. Acesso em: 12 maio 2019.

INTERNACIONAL GAY \& LESBIAN TRAVEL ASSOCIATION. IGLTA. Fort Lauderdale, 2020. Disponível em: https://www.iglta.org/ Acesso em: 02 fev. 2020.

LAW, R; NGAI, C. Usability of travel sites: A case study of the perceptions of Hong Kong travelers. Journal of Hospitality \& Leisure Marketing, v. 13, n. 2, p. 19-31, 2005. Disponível em:

https://www.tandfonline.com/doi/abs/10.1300/J150v13n02_03. Acesso em: 19. out.2020

LE COADIC, Yves-François. A ciência da informação. Brasília: Briquet de Lemos, 1996. 119p.

MAGALHÃES, M. C. A invisibilidade lésbica em blogs de turismo brasileiros. 2018. Trabalho de Conclusão de Curso (Pós-graduação em Marketing Digital) - UNICEUB, Centro Universitário de Brasília, 2018. Disponível em: https://repositorio.uniceub.br/jspui/handle/235/12302. Acesso em: 08 ago. 2019.

MOROSAN, C.; FESENMAIER, D. R. A conceptual framework of the persuasive architecture of tourist sites: propositions and premises. In: (Mariana Sigala, Luisa Mich e Jamie Murphy) Information and communication technologies in tourism. Springer, Viena, 2007. p. 243-254. Disponível em: https://link.springer.com/chapter/10.1007/978-3-211-69566-1_23. Acesso em. 19. out. 2020

NASCIMENTO, F. A. Memória da militância: a contribuição da Organização do Conhecimento para a reconstrução da memória do movimento LGBT da região do Cariri cearense. 2015. Dissertação (Mestrado em Ciência da Informação). 2015. - Universidade Federal de Pernambuco, 2015. Disponível em: https://repositorio.ufpe.br/handle/123456789/15380. Acesso em: 08 ago. 2019.

OLIVEIRA, H. P. C.; VIDOTTI, S. A. B. G. V. Al digital: conexões interdisciplinares dentro da abordagem sistêmica. In: CAVALCANTE, L. E.; PINTO, V. B.; VIDOTTI, S. A. B. G. V. (Ed.). Ciência da informação e contemporaneidade: tessituras e olhares. Fortaleza: Edições UFC, 2012. p. 184-202. 
OLIVEIRA, H. P. C.; VIDOTTI, S. A. B. G. Dos ambientes informacionais às ecologias informacionais complexas. Informação \& Sociedade, Joao Pessoa, v. 26, n. 1, p. 91-101, 2016. Disponível em:

https://periodicos.ufpb.br/ojs2/index.php/ies/article/view/29438. Acesso em 19 out. 2020.

OLIVEIRA, M. A influência dos eventos na taxa de ocupação hoteleira: study case - Montebelo Viseu Hotel \& Spa. 2014. Dissertação (Mestrado em Turismo com especialização em Gestão Estratégica de Eventos). 2014. Escola Superior de Hotelaria e Turismo do Estoril, 2014. Disponível em: https://comum.rcaap.pt/bitstream/10400.26/8757/1/2014.04.005_.pdf. Acesso 19 out. 2020.

ORGANIZAÇÃO MUNDIAL DO TURISMO. Introdução ao turismo. São Paulo: Roca, 2001.

REIS, G. A. Centrando a Arquitetura de Informação no usuário. Dissertação (Mestrado em Ciência e Artes). 2007. - Universidade de São Paulo, 2007. Disponível em: https://www.teses.usp.br/teses/disponiveis/27/27151/tde23042007-

141926/publico/GuilhermoReisCentrandoArquiteturadeInformacaonousuario.pdf . Acesso 19 out. 2020.

ROSENFELD, L.; MORVILLE, P. Information architecture for the World Wide Web. Sebastopol: O’Reilly, 1998.

ROSENFELD, L.; MORVILLE, P.; ARANGO, J. Information architecture: for the web and beyond. Sebastopol: O'Reilly, 2015.

SANCHES, T. C; MANCINI, L. A; NASCIMENTO, M. A. N. Turismo GLS e o perfil do seu público consumidor na região norte do Paraná. Turismo-Visão e Ação, Camboriú, v. 13, n. 1, p. 81-95, 2011. Disponível em: https://www.redalyc.org/pdf/2610/261056076006.pdf. Acesso em: 19 out. 2020.

SANCHEZ, F. A. Encontrabilidade da informação em repositórios digitais: um estudo de eye-tracking nos repositórios institucionais da USP, UNESP e UNICAMP. 2018. Dissertação (Mestrado em Ciência da Informação) Faculdade de Filosofia e Ciências, Universidade Estadual Paulista, Marília, 2018. Disponível em: https://repositorio.unesp.br/handle/11449/154348. Acesso em: 19 out. 2020.

STRAIOTO, F. A Arquitetura da Informação para a World Wide Web: um estudo exploratório. 2002. Dissertação (Mestrado em Ciência da Informação) Faculdade de Filosofia e Ciências, Universidade Estadual Paulista, 2002.

TRIGO, L. G. Ascensão do prazer na sociedade atual: turismo GLS. In: NETTO, Alexandre Panosso; ANSARAH, Marília Gomes dos Reis (Org.). Segmentação do mercado turístico: estudos, produtos e perspectivas. Barueri: Manole, 2009. p. 141-163. 
VECHIATO, F. L. Repositório digital como ambiente de inclusão digital e social para usuários idosos. 2010.183f. Dissertação (Mestrado em Ciência da Informação) - Faculdade de Filosofia e Ciências, Universidade Estadual Paulista, Marília. Disponível em: https://www.marilia.unesp.br/Home/PosGraduacao/Cienciadalnformacao/Dissertacoes/vechiato_fl_me_mar.pdf. Acesso em: 19 out.2020

VECHIATO, F. L; VIDOTTI, S. A. B. G. Encontrabilidade da informação. São Paulo: Cultura Acadêmica, 2014.

VIDOTTI, S. A. B. G.; CUSIN, C. A.; CORRADI, J. A. Mesa: Acessibilidade digital sob o prisma da Arquitetura da Informação. In: GUIMARÃES, J. A. C.; FUJITA, M. S. L. (orgs) Ensino e pesquisa em Biblioteconomia no Brasil: a emergência de um novo olhar. São Paulo: Cultura Acadêmica, 2008.

\title{
GUIDELINES FOR LGBTQ TOURISM WEBSITES BASED ON INFORMATION ARCHITECTURE ELEMENTS
}

\begin{abstract}
Introduction: This paper, part of the need for digital informational environments to consider the provision of information and vocabularies used, to present informational content with structures and languages to a specific community, in this case the LGBTQ community. Objective: The objective of this research is to propose improvements and recommendations on LGBTQ tourism websites based on the theoretical apparatus of Information Architecture, aiming to optimize access and findability of tourist information on these websites. Methodology: Methodologically, it is a qualitative, descriptive and analytical research. It is justified by the relevance of the theme, Information Architecture in the context of gender and sexuality studies, by presenting the issue of groups so vulnerable to prejudice and violence in our society. Creating then place for reflection power through LGBTQ tourism websites with information well organized as a means of promoting the rights, struggles, aspirations and fears of these groups. Results: As a result, a group of guidelines were presented to point out fundamental elements of application to the structural principles of Information Architecture for meeting the informational needs of the LGBTQ community on tourism websites. Conclusions: The LGBTQ Community has specific informational needs, which are sometimes found in the website interface, these needs are expressed through the Pajubá vocabulary and which must be involved in the context of Information Architecture.
\end{abstract}

Descriptors: Information Architecture. LGBTQ Tourism. Genre. Sexuality.

\section{DIRECTRICES PARA LOS SITIOS WEB DE TURISMO LGBTQ BASADAS EN LOS ELEMENTOS DE LA ARQUITECTURA DE LA INFORMACIÓN}




\section{RESUMEN}

Introducción: esta investigación se basa en la necesidad de entornos informativos digitales para considerar la información y los vocabularios utilizados para presentar contenido informativo con estructuras e idiomas a una comunidad específica, en este caso la comunidad LGBTQ. Se justifica por la relevancia del tema, Arquitectura de la información en el contexto de los estudios de género y sexualidad, al presentar el tema de grupos tan vulnerables a los prejuicios y la violencia en nuestra sociedad. Por lo tanto, crear un lugar para la reflexión del poder a través de sitios web de turismo LGBTQ con información bien organizada como un medio para promover los derechos, luchas, ansiedades y temores de estos grupos. Objetivo: Con este fin, el objetivo es proponer pautas en los sitios web de turismo LGBTQ basadas en el aparato teórico de la Arquitectura de la Información, con el objetivo de optimizar el acceso y la posibilidad de encontrar información turística en estos sitios web. Metodología: Metodológicamente, esta es una investigación cualitativa, de naturaleza descriptiva y analítica, y se refiere a un análisis de observación directa que no participa en los resultados de una investigación realizada previamente por Brito (2019); Brito y Matias (2019) apuntan a la propuesta y presentación de las directrices de Arquitectura de la Información en los sitios web de turismo LGBTQ de Brasil. Resultados: Como resultado, se presentó un grupo de directrices para señalar elementos fundamentales de aplicación a los principios estructurales de la Arquitectura de la Información para satisfacer las necesidades de información de la comunidad LGBTQ en los sitios web de turismo. Conclusiones: La Comunidad LGBTQ tiene necesidades informativas específicas, que a veces se encuentran en la interfaz del sitio web, estas necesidades se expresan a través del vocabulario Pajubá y que deben estar involucradas en el contexto de la Arquitectura de la Información.

Descriptores: Arquitectura de la información. Turismo LGBTQ. El género. Sexualidad.

Recebido em: 26.10 .2020

Aceito em: 08.02.2021 